\title{
HIV risk and barriers to care for African-born immigrant women: a sociocultural outlook
}

\author{
This article was published in the following Dove Press journal: \\ International Journal of Women's Health \\ 8 June 2017 \\ Number of times this article has been viewed
}

\author{
Olihe N Okoro' \\ Shanasha OWhitson ${ }^{2}$ \\ 'Department of Pharmacy Practice \\ and Pharmaceutical Sciences, College \\ of Pharmacy, University of Minnesota, \\ Duluth, ${ }^{2}$ Community Partnership \\ Collaborative 2.0, Minneapolis, \\ MN, USA
}

Background: Data from the Minnesota Department of Health (MDH) HIV/AIDS Surveillance Report 2015 show that African-born (AB) women continue to be disproportionately affected by HIV. In 2015, these women accounted for more than half (54\%) of all new cases of HIV reported among females in Minnesota and 34\% of all known female cases in the state. This study was a needs assessment for HIV pre-exposure prophylaxis (PrEP) in vulnerable subgroups within the $\mathrm{AB}$ population and adequacy of HIV care for $\mathrm{AB}$ persons. The primary objective of this study was to gain an insight into the strategies that will limit the spread of HIV infection and enhance HIV care among AB immigrants.

Methods: Community advocates, community-based organizations (CBOs), clinicians, and other HIV-related service providers were invited to participate in a focus group, structured interview or complete an assessment tool using the same questionnaire about HIV and PrEP among $\mathrm{AB}$ persons. A thematic analysis was then conducted on the open-ended questions addressing perceived barriers.

Results: Findings suggest the following gender-specific sociocultural factors that drive HIV transmission and constitute barriers to HIV treatment for $\mathrm{AB}$ women: domestic/intimate partner violence, gender-biased stigma, discriminatory cultural beliefs and normative values/ expectations, unprotected sex with husbands who have sex with other men, gender discordance in health care (preference for female provider), and sexual/reproductive health illiteracy.

Recommendation: Based on recommendations, a community-based sexual and reproductive health education is being initiated with a curriculum that will be 1) broad (inclusive but not limited to HIV), 2) culturally sensitive/responsive, and 3) at appropriate literacy level for all women, including those who have little or no formal education.

Keywords: African-born women, HIV/AIDS, reproductive health, intimate partner violence

\section{Introduction}

In the US, the reported rates of HIV diagnosis among African-born (AB) immigrants have been as high as six times that of the general US population. ${ }^{1}$ Available data also point to a disproportionate burden of HIV among AB women. ${ }^{2}$ Crude diagnosis rates among $\mathrm{AB}$ women are 12 times higher than that of women in the general population ${ }^{3}$ and up to 36 times greater than the estimated incidence in their White US-born counterparts. ${ }^{4}$ Unadjusted diagnosis rates among AB women remain higher even compared with other Black women, including US-born and other Black foreign-born women. ${ }^{5}$ The difference in crude diagnosis rates by gender among AB persons in the US closely mirrors the distribution of new cases of HIV observed in Sub-Saharan Africa. ${ }^{6}$ Available data also demonstrate higher rates of infections among AB women compared to those in $\mathrm{AB}$ men. ${ }^{7,8}$ There is some evidence that a good number of $\mathrm{AB}$ women diagnosed with HIV contracted the virus while in their country of origin. ${ }^{7}$ However,
Correspondence: Olihe N Okoro Department of Pharmacy Practice and Pharmaceutical Sciences, College of Pharmacy, University of Minnesota, 235 Life Science, II 10 Kirby Drive, Duluth, MN 55812, USA

Tel +I 2187266036

Fax +I 2187266500

Email ookoro@d.umn.edu
International Journal of Women's Health 2017:9 421-429

Dovepress if in 8

http://dx.doi.org/10.21474JWHS12935 (c) (1) (-) 20170 koro and Whitson. This work is published and licensed by Dove Medical Press Limited. The full terms of this license are available at https://www.dovepress.com/terms.php (c) hereby accept the Terms. Non-commercial uses of the work are permitted without any further permission from Dove Medical Press Limited, provided the work is properly attributed. For permission for commercial use of this work, please see paragraphs 4.2 and 5 of our Terms (https://www.dovepress.com/terms.php). 
there is reason to believe that a significant proportion may also contract the disease here in the US. In the metropolitan cities where there are large populations of $\mathrm{AB}$ immigrants, it is common to find these groups living in areas of high HIV prevalence. ${ }^{9}$

The aggregation of HIV data for all Black persons regardless of continental origin is a challenge to obtaining an accurate HIV epidemiological profile of the AB population. The general consensus is that current statistics are likely an underestimation of the true number of $\mathrm{AB}$ persons living with HIV, on account of the large numbers of undocumented AB immigrants and the reluctance to test for HIV.

In Minnesota, HIV prevalence and incidence rates are concentrated in the Minneapolis/St Paul metro area and the surrounding suburbs. ${ }^{10}$ AB persons are concentrated in this area and also have a disproportionately higher incidence of HIV infection compared to that in other racial/ethnic groups. While constituting an estimated $1 \%$ of the state's population in $2015, \mathrm{AB}$ persons accounted for $20 \%$ of new diagnosis. ${ }^{10}$ HIV prevalence by gender is markedly different for this group compared with US-born persons. At the end of 2015 , AB women accounted for $57 \%$ of all known cases among AB persons living in Minnesota in contrast to US-born women who accounted for only $18 \%$ of all known cases among US-born persons in the state. ${ }^{11}$ In 2015 alone, AB women accounted for $54 \%$ of new diagnosis of HIV among adult females in the state. ${ }^{10}$ The majority of HIV cases are among women from Ethiopia, Liberia, and Kenya. ${ }^{11}$

Biological and anatomical factors are implicated in women's risk for HIV. ${ }^{12}$ In heterosexual, serodiscordant couples, male-to-female HIV transmission per coital encounter carries twice the risk compared to that with femaleto-male transmission. ${ }^{13}$ Concurrent sexually transmitted infection (STI) in an HIV-infected partner has also been shown to increase a seropositive person's susceptibility to HIV transmission. ${ }^{13}$ Africans/African Americans currently have the highest rates of STIs in Minnesota. ${ }^{14,15}$ While these may explain in part the high HIV prevalence and incidence rates among $\mathrm{AB}$ women, the magnitude of the disparity compared with women of other race/ethnicity suggests other contributing factors.

Qualitative studies have explored the social context of HIV and related needs in African immigrant communities in the US. ${ }^{16-20}$ Key emerging themes from these studies include 1) high levels of stigma, ${ }^{16-19}$ 2) structural and health care system-related barriers to screening and care, ${ }^{16,18,19} 3$ ) beliefs that foster misperception of risk and treatment and associated sexual and health-seeking behaviors, ${ }^{17,19}$ and 4) fear of deportation due to undocumented status. ${ }^{16}$ Additional literature supports the higher vulnerability of $\mathrm{AB}$ women to HIV due to economic dependence, ${ }^{16}$ lower literacy levels associated with limited access to relevant resources, ${ }^{17}$ and stronger stigma associated with women acquiring HIV compared with men. ${ }^{18}$

The current needs assessment was conducted on the general $\mathrm{AB}$ immigrant population; however, themes that illustrate factors that uniquely impact $\mathrm{AB}$ women - a priority population - emerged, and these are highlighted in this particular report.

\section{Study objective}

The primary objective was to gain an insight into the factors that drive the spread of HIV infection among AB immigrant women living in Minnesota and identify the barriers to HIV care for this population from the perspective of persons with high exposure to members of the priority population as their clients and/or as fellow community members.

\section{Methods \\ Study participants and sampling}

Participation in this needs assessment was sought from a broad range of stakeholders - health care professionals, service providers, and community advocates - most of whom were also members of the $\mathrm{AB}$ immigrant community. The final sample included 30 participants (Table 1). Persons living with HIV were not included in this assessment.

\section{Inclusion criteria}

Persons targeted for recruitment were those who had extensive interaction with members of the $\mathrm{AB}$ community.

Table I Demographic characteristics of key informants

\begin{tabular}{ll}
\hline & $\mathbf{n}$ \\
\hline Professional/stakeholder capacity & \\
Physicians & 5 \\
Medical case managers & 9 \\
PrEP case managers & 4 \\
Community advocates & 6 \\
CBO program director or CEO & 3 \\
HIV outreach coordinator & $\mathrm{I}$ \\
HIV tester & $\mathrm{I}$ \\
Licensed alcohol and drug counselor & $\mathrm{I}$ \\
Gender distribution & \\
Female & 22 \\
Male & 8 \\
Continental origin & \\
African-born immigrant & 28 \\
African American & 2 \\
Total no of participants & 30 \\
\hline
\end{tabular}

Abbreviations: PrEP, pre-exposure prophylaxis; $\mathrm{CBO}$, Community-based Organizations; CEO, Chief Executive Officer. 
Potential participants were identified using one or more of the following criteria:

i. Health care professionals and HIV service providers including doctors, nurses, HIV community testers, case managers, social workers, community advocates, housing specialists, prevention specialists, and outreach workers - particularly those with the majority of their clients being from the $\mathrm{AB}$ immigrant community.

ii. HIV services providing organization, Community-based Organization (CBO) who receive Ryan White Funding and work directly with the $\mathrm{AB}$ population.

iii. Worked/working for an $\mathrm{AB}$ agency or are a part of an $\mathrm{AB}$ committee, collaborative, or health action group focused on $\mathrm{AB}$ health and/or social issues.

iv. Identified by others as a "Community Champion" defined here as someone who does not necessarily work in the field of HIV but has advocated for AB persons living with HIV through their involvement in any HIV-related volunteer or service-providing work.

\section{Data collection}

The study was conducted as a participatory needs assessment. A participatory needs assessment is conducted to gain an insight into the needs of a specified population and includes needs associated with the broader determinants of health. ${ }^{21}$ Professionals and community members partner to identify needs and develop an action plan to address them. This assessment focused on HIV and used both formal and informal approaches to collect information from key informants in order to understand the drivers of HIV transmission and barriers to care in the AB population.

Participants were recruited through purposeful sampling based on the stated inclusion criteria. A snow-balling technique, whereby participants referred the investigator to other potential participants, was also adopted.

Due to time constraints and convenience, participants had the option of participating in one of three focus groups $(n=7, n=8$, and $n=8)$ or filling out a questionnaire through a one-on-one interview or by self-administration $(n=8)$. One of the focus group participants also filled out the questionnaire for the agency they represent. The same set of questions was used for each method of data collection. The same investigator conducted all the interviews and facilitated the focus groups. Interviews lasted between 30 minutes and 1 hour. The focus groups lasted between 60 and 90 minutes. Questions centered on their experiences with providing care or other services to the $\mathrm{AB}$ immigrant population; barriers and facilitators for their clients or patients with regard to HIV prevention and specifically around the use of pre-exposure prophylaxis (PrEP); and other health care-related challenges experienced by $\mathrm{AB}$ clients. Extensive notes were taken during the focus groups and interviews when participants did not consent to be audiorecorded. Text boxes were provided for responses in the paper-based questionnaire for the selfadministered survey.

\section{Data analysis}

A thematic analysis of the audio recordings, notes, and written responses to open-ended questions was conducted on data for the general $\mathrm{AB}$ population. Initial classification of data was according to the question to which participants were responding. The second investigator read through the data repeatedly, writing down key information from the responses. The contextual meaning of these pieces of information formed themes that were then grouped into categories based on their relationship. The categories included the following - socioeconomic factors, stigma associated with seeking HIV care, cultural beliefs and norms, health care system-related barriers, linguistic and cultural barriers, patient-related factors, and unique risk factors. Some of these categories had gender-specific factors. Further exploration of all responses that made reference to women led to the extraction of gender-specific themes. Given the disproportionate burden of HIV in this subpopulation, these are the themes highlighted in this report. Recurrence of themes was not quantified as questions were not gender specific. Responses therefore differed based on service providing (clinical, volunteer, or otherwise) and the mix of clients served. A written report of the study findings was sent to the participants - to review and confirm that the data as presented were an accurate reflection of their perspectives. Revisions and amendments were made based on feedback received.

\section{Ethics and compliance statement}

This research was submitted to the institutional review board of the University of Minnesota and was judged exempt from review under federal guidelines 45 CFR Part 46.101 (b) category \#2 SURVEYS/INTERVIEWS. Consent is not required for observational surveys or questionnaires under this federal guideline.

\section{Findings}

Our findings suggest that there are gender-specific sociocultural factors that drive HIV spread and constitute barriers to HIV-related services for $\mathrm{AB}$ women. These included domestic/intimate partner violence, gender-biased stigma, 
gender-discriminatory cultural norms and expectations about sex, unprotected sex with husbands who are men who have sex with men (MSM), gender discordance in health care (preference for a female provider), and sexual/reproductive health illiteracy.

\section{Domestic/intimate partner violence}

Participants reported that cultural perceptions and normative beliefs about gender roles fostered and re-enforced domestic or intimate partner violence toward women. They pointed out that culturally women were expected to be subordinate to men and were socialized accordingly. Many AB women, therefore, are not empowered to deal with issues of violence directed at them in an intimate relationship (including marriage). Culturally, leaving a marriage is generally viewed as the woman's failure. Thus, these women tend to adapt to the situation as their "fate". They are generally unwilling to discuss the occurrence even among peers. From participants' comments, intimate partner violence was perceived as a hidden problem that the community was either in denial of or accepting of as "normal". The result, they said, was that AB women often choose to stay in abusive relationships. This, participants said put them at greater risk of acquiring HIV, because they are unable to demand faithfulness from their significant other or negotiate condom use for fear of being harmed or deserted.

One of the issues that stem from HIV-related domestic violence or intimate partner violence occurs after a husband is confronted with a possible exposure, or used in the form of an exploitation tactic to control their wife's behavior and movement and overall livelihood. [Female FGD participant; AB community member]

\section{Gender-biased HIV stigma}

There was general consensus from participants that there was a lot of stigma associated with HIV within the AB community. However, they acknowledged that it was significantly greater when directed toward women. Stigma, they reported, was particularly challenging for women experiencing domestic and/or intimate partner violence. Even though these women were obviously the victims of this circumstance, if they became HIV positive, they were still stigmatized. With this, AB women who discover they have become HIV positive have the critical considerations of where to access HIV services without others in the community finding out. For these women, the shame and guilt are not just personal but appear to affect the family if their HIV status is disclosed. This, participants reported, could potentially delay and in some cases even prevent linkage to much needed HIV care. Even when care is initiated, participants reported that perceived (and internalized) stigma may result in nonadherence and loss to follow-up.

People who are in need of services do not come for them because if the topic of HIV is visual or talked about people tend not to want to be involved. Now if you throw in the mix a woman who is being abused her options are limited, who can she trust and how does she access service without shame or guilt that will be extended to the family if she asks for help or lets people know what is going on. [FGD participant; $\mathrm{AB}$ community member and $\mathrm{CBO}$ founder/director]

\section{Gender-discriminatory cultural norms and expectations}

Participants acknowledged that cultural beliefs, norms, and values of African cultures generally place different expectations on women versus men with regard to sex. Discussion on sexually related issues is culturally taboo, particularly among women. A woman talking about sex is generally frowned upon as this is considered indicative of promiscuity. Women, therefore, are not raised talking about sex, sexuality, or sexual health. They are generally not encouraged to openly discuss these issues with their husband (even in the context of marriage), a significant other, or even peers. According to participants, many women in the $\mathrm{AB}$ population have never talked about sex which then poses a challenge for them in terms of seeking information about sexual health or asking questions regarding risk factors and options for HIV prevention.

Women due to cultural traditions, cultural taboos, stigmas and the way that women are child reared are not able to talk about sex or sexual health issues openly with a husband, partner, or peers. [FGD participant; AB community member]

A couple comes in but because of the taboo and traditional views of that culture a woman may be afraid to ask her case manager about a sexual health prevention service or program because of the shame or fear of how her husband will react once they leave the office. How does she even begin to talk about the issue of condom use or how to put a condom on or where to get free condoms if she cannot even talk about sex with her case manager because of the taboos and deep-rooted cultural impacts talking about sex put on an already strained relationship because one partner may be positive or for fear of being accused of having an affair. [Interview respondent; medical case manager] 


\section{Unprotected sex with MSM husbands}

Participants reported that MSM who are HIV positive are having unprotected sex with married men who are not HIV positive. And these married men were reportedly not asking their partners about their HIV status. There is, therefore, no ongoing conversation between the married man and the MSM partners or between the married partner and his spouse. The women married to these men are not empowered to negotiate safe(r) sex, for example, the use of condom. Married men who are having sex with men who are HIV positive are thus putting both themselves and their wives at very high risk of contracting HIV.

[...] he (outreach worker) has men on his case load who are HIV positive and these men communicated to him that the men that they are sleeping with are not HIV positive [but are] African Born married men and the fact that these men are not using condoms and the fact that the African Born married men who are not HIV positive are not asking the men who are HIV positive who they (the married men) are sleeping with if they are positive and they are not discussing condom use nor are they using condoms each and every time they have sex. Which means, African Born married men who are having sex with men who are HIV positive are putting themselves and their wives at very high risk of contracting HIV[...] [FGD participant; community outreach program coordinator]

\section{Gender discordance in health care encounters (preference for a female provider)}

Given the challenge of discussing sexual health-related issues, participants reported that $\mathrm{AB}$ women would generally prefer a female health care provider. The reason was that $\mathrm{AB}$ women may not feel as comfortable discussing sexual health-related issues with male providers. However, many of these women, reportedly, may not have the privilege of choice of provider based on things such as the type of insurance coverage and where they access care. Even when they do have a choice, many of these women may not feel empowered enough to advocate for themselves and express their preference of a female provider. With male health care providers, these women are often not open with challenges and concerns they may have pertaining to sexual health. As a result, they may not get the relevant information to safeguard against HIV.

\section{Sexual/reproductive health illiteracy}

Participants reported that sex and reproductive health are not discussed with $\mathrm{AB}$ women from a young age. This absence of health education, participants noted, impacts the $\mathrm{AB}$ woman throughout her lifetime. Reportedly, they grow up mostly ignorant of issues around their sexuality and their reproductive system. This lack of knowledge was said to lower their risk perception about HIV and other sexually transmitted diseases, thereby increasing their risk. These same women, they reported then grow up to become mothers who lack the relevant knowledge and are not able to educate their daughters even if they wanted to.

How do you ask women to talk with their children about sex when that is not something African women do? That is not something African families do? Many of the women have never had open conversations about sex. If you yourself do not know how to start the conversation. How do you start the conversation?[...] Women, African women have to first be empowered about who they are and their bodies before we can get to -----, there has to be that basic information and training and education first. [FGD participant; $\mathrm{AB}$ community member and advocate]

In addition, the low level of literacy around sexuality reproductive health was also identified as a barrier to conventional HIV prevention efforts that may assume clients to have some level of knowledge about the female physiology and reproductive system. The observation made was that due to self-consciousness about this lack of basic knowledge, $\mathrm{AB}$ women even in settings where HIV-related information is shared or taught would tend to refrain from asking questions about things they did not understand.

\section{Recommendation from $A B$ women participants}

The major recommendation for targeted HIV prevention among $\mathrm{AB}$ women was to educate women with a broad sexual and reproductive health curriculum. Participants emphasized that for African women, the information and awareness about HIV would be more effective coming through education around women's health including sexual health, childbearing, and fertility. Information on HIV and other sexually transmitted diseases could then be incorporated. They recommended that information is offered generally as opposed to HIV-specific education. This, they agreed would buffer some of the HIV-related stigma. That way, women who are HIV positive (or at very high risk) can have access to relevant information, resources, and services without being identified as having HIV. Respondents stressed that HIV prevention and education efforts for $\mathrm{AB}$ women have to be marketed as relevant knowledge for everyone, targeting those at risk but 
not seen as being directed at those living with HIV/AIDS. Another point of emphasis was the need for the curriculum to be culturally responsive and at a level of comprehension for women who have little or no formal education.

This has to be a women's health education institute or some type of educational setting, that way it will take some of the pressure off the stigma if people are getting educated in a school type setting. That way people who access this information cannot be looked at any type of way or identified as having HIV, but can get access to the information and services they need[...] [FGD participant;

$\mathrm{AB}$ community member]

In terms of implementation, particularly to address the taboos associated with talking about sex, one suggestion was to have a safe place where $\mathrm{AB}$ women could begin to have conversations around sex, condom use, and sexuality. Respondents said this could be organized as weekly or monthly support groups that go through a dialog guided by a curriculum. Suggested content in the proposed curriculum included sexual health information for women, communication skills on how to talk with their husbands or other significant partners about sex, and information on resources for women in abusive situations to enable them to safe guard themselves against acquiring HIV if they are having trouble negotiating sex (for example, using PrEP). All of these topics, respondents emphasized, should be done in a culturally appropriate and responsive manner.

There have to be groups held regularly for women to come together and talk about their sexual needs as well as sexual health issues like HIV and intimate partner violence that impact their sexual health and their physical health. Women have to create groups and have health fairs and have access to service providers who are familiar with intimate partner violence and how this impacts their HIV and how this impacts the way they interact with their partners and how they teach their children about sex[...] There can also be weekly or monthly support groups that go through a dialogue or a curriculum involving sexual health for women, techniques on how to talk with your husband or partner about sex, and how women in domestic violence can be on PrEP as a safe guard to protect themselves from HIV if they are having trouble negotiating sex with an abusive partner and how this can be done if the proper education and information is given through these outlets. [FGD participant; AB community member]
It has to be in a setting like this [referring to the focus group], just women, all connected, all talking and sharing together. [FGD participant; community advocate]

There was also some discussion on the need to ensure buy-in from $\mathrm{AB}$ men by educating the male community and religious leaders who they hoped would become advocates for the women.

\section{Discussion}

Previous studies support the themes found in the current research. For example, the stigma associated with having $\mathrm{HIV}$ is a barrier to care in this population. HIV-related stigma though prevalent in all populations appears to be much stronger among Africans. This is based on the commonly held cultural and/or religious beliefs that HIV/AIDS is a punishment for illicit sexual behavior or other misdeeds. ${ }^{22}$ Women particularly are often labeled as indecent and promiscuous when diagnosed with HIV. ${ }^{22,23}$ In addition, women living with HIV are more often than not seen as the "carriers" infecting others and not as victims who were infected by others. ${ }^{24}$ African women, therefore, continue to face greater stigma than their male counterparts. ${ }^{25,26}$ These attitudes are not surprising since African cultures, for the most part, have been historically notorious for gender discrimination. The dominant patriarchal family and societal structure fosters normative values that generally accord an inferiority status to the woman and fails to recognize her rights - sexual and otherwise. ${ }^{27}$ This gender-related HIV stigma (both experienced and internalized) has been associated with reluctance to get tested, lack of disclosure of HIV status, delayed linkage to HIV care, and lack of retention in HIV treatment among African women. ${ }^{28}$

Drawing on our findings, there is a reason to believe that while $\mathrm{AB}$ immigrants living in the US are subject to US laws, cultural norms and values appear to be so strongly entrenched that they still influence behaviors and shape expectations. Several studies have demonstrated an association between intimate partner violence and HIV infection among women in Africa. ${ }^{29-33}$ The culturally defined roles of women in some African cultures are limited to childbearing, housekeeping, and community service. ${ }^{27}$ Women in some African cultures, regardless of level of education and career achievement, are generally regarded as second class citizens, not having the same sexual rights as men nor deserving of same treatment, and expected to be subordinate to men especially within the context of sexual relations. ${ }^{34,35}$ Failure to comply with 
conjugal demands gives rise in part to the high prevalence of intimate partner violence in this population. ${ }^{34} \mathrm{AB}$ immigrant women who have little or no formal education or professional skill are usually unemployed and have low English proficiency. AB women who in addition are undocumented may, therefore, be reluctant to break off an abusive relationship because of their economic dependence on their partner and/or threats of deportation.

MSM was another important finding of this study. Homosexuality in the African culture is taboo and in many countries has been criminalized. ${ }^{36}$ There is strong evidence that MSM in areas of such high stigma are likely to continue same-sex sexual relations after becoming married. ${ }^{36}$ In keeping with societal expectations, African MSM are known to get married to women and have children but continue to engage in sex with other men often without their wives' knowledge. Research findings demonstrate that globally, in every context, MSM are at relatively higher risk of acquiring HIV compared to the general population. ${ }^{37,38}$ Even when $\mathrm{AB}$ women know that their husbands are having sex with other partners, the culturally defined role of subordination undermines their ability to confront their partners about their infidelity. They are also for the most part unable to negotiate condom use even in the face of the imminent risk of contracting STIs including HIV. ${ }^{34,39}$ Findings from this assessment highlight the challenge $\mathrm{AB}$ women face with regard to initiating conversations around safer sex practices, which conventional public health interventions advocate for. Targeted HIV interventions, therefore, need to take this unique sociocultural context into consideration.

Our findings suggest that health-seeking behaviors in this priority population may be influenced by gender of provider. Religious considerations in many African cultures particularly the Islamic religion prohibit interactions between females and males other than their husbands. ${ }^{40}$ Immigrant women from these cultural or religious backgrounds, and particularly those who are less educated, generally have a preference for receiving care from female versus male health care providers. ${ }^{41}$ Generally, women from African countries prefer to talk to a female provider about sexual health or reproductive health issues. ${ }^{42}$ However, these women may not be proactive in expressing their gender preferences especially coming from cultures where women are not expected to be assertive. If this preference is expressed, the health facility where they have access to care may not have the capacity to accommodate every client's preference. The findings from the current study underscore the discomfort
AB females may have in talking about their sexual health with male providers. Thus, even $\mathrm{AB}$ women who have access to health care may not have their reproductive health needs met including receiving information that could be helpful in HIV prevention.

From a health care system perspective, steps toward more effective care for $\mathrm{AB}$ women may include 1) asking about their gender preference in provider and matching them accordingly, 2) making efforts to recruit more female providers especially in facilities whose clientele consists of a good proportion of members of this priority population, and 3 ) cultural competency training for current providers to enable them give more culturally responsive care.

The lack of sexual/reproductive health literacy is also a key issue. In a review of the literature, Burgoyne and Drummond documented evidence of low levels of knowledge and misconceptions about sexually transmitted disease among African women. ${ }^{43}$ These have also shown to hold true for African immigrant women. ${ }^{44,45}$ Low levels of education have also been correlated with lower sexual health knowledge in this population. ${ }^{43}$ Given the cultural lenses through which $\mathrm{AB}$ immigrant women view sex and related subjects and taking into account the low literacy level of the more vulnerable subgroups within this population, sexual and reproductive health education needs to be both culturally responsive and at an appropriate literacy level. To date, there is no such curriculum tailored to the unique needs of this population.

\section{Limitations}

Due to the exploratory nature of the assessment, the sample size was small and participants' opinions may not be representative of those of the target population. However, care was taken to ensure diversity and inclusion of various stakeholders.

The views presented here are those with reference to $\mathrm{AB}$ women in general and do not capture issues that may be unique to each specific African country of origin or take into account differences that do exist between cultures even within one country. However, regarding HIV prevention and health care-related needs, there was a general agreement among respondents that the challenges identified were mostly similar for all subgroups.

While the inclusion of quotes is consistent with the reporting of qualitative data, we do not have direct quotes reflecting some of the discussions around the reported themes. Some of the participants were not comfortable with being audiorecorded and therefore did not give consent. 
As a result, only quotes from recorded or written responses have been included.

\section{Next steps}

As a follow-up to the strong recommendation regarding the institution of a community-based sexual/reproductive health education for AB women, curriculum development has been initiated. Five AB women from four African countries have been engaged and are currently adapting a well-used, nationally recognized sexual health curriculum for the planned HIV intervention. The adapted curriculum will subsequently be reviewed by four to six other $A B$ women who will provide feedback on content. The curriculum development team will also conduct focus groups with diverse groups of $\mathrm{AB}$ women to ensure comprehension and cultural responsiveness of this newly adapted curriculum. In a proposed pilot study, the adapted curriculum will then be used to educate a sample of AB women. Participants will be evaluated for change in relevant knowledge, attitude toward sex (including discussions, and related behaviors), risk perception, and self-efficacy to negotiate safe sex where possible.

\section{Conclusion}

The disproportionate burden of HIV among AB immigrant women in Minnesota and in the US as a whole is in part driven by sociocultural factors unique to this population. As such, conventional approaches to HIV prevention and mainstream interventions to facilitate linkage to and retention in care may not be effective in this priority group. A broad-based, culturally sensitive sexual and reproductive health curriculum that is taught in a safe space and at a level of literacy comprehensible to $\mathrm{AB}$ women who have little or no formal education is therefore strongly recommended.

\section{Disclosure}

The authors report no conflicts of interest in this work.

\section{References}

1. Blanas DA, Nichols K, Bekele M, Lugg A, Kerani RP, Horowitz CR. HIV/AIDS among African-born residents in the United States. J Immigr Minor Health. 2013;15(4):718-724.

2. Kerani RP, Kent JB, Sides T, et al. HIV among African-born persons in the United States: a hidden epidemic? J Acquir Immune Defic Syndr. 2008;49(1):102-106.

3. Hall HI, Song R, Rhodes P, et al. HIV Incidence Surveillance Group. Estimation of HIV incidence in the United States. JAMA. 2008; 300(5):520-529.

4. Centers for Disease Control and Prevention (CDC). Subpopulation estimates from the HIV incidence surveillance system - United States, 2006. MMWR Morb Mortal Wkly Rep. 2008;57(36):985-989.
5. Johnson AS, Hu X, Dean HD. Epidemiologic differences between native-born and foreign-born black people diagnosed with HIV infection in 33 U.S. states, 2001-2007. Public Health Rep. 2010; 125(suppl 4):61-69.

6. UNAIDS. World AIDS Day Report. Geneva: UNAIDS; 2011.

7. Harawa NT, Bingham TA, Cochran SD, Greenland S, Cunningham WE. HIV prevalence among foreign- and US-born clients of public STD clinics. Am J Public Health. 2002;92(12):1958-1963.

8. Akinsete OO, Sides T, Hirigoyen D, et al. Demographic, clinical, and virologic characteristics of African-born persons with HIV/AIDS in a Minnesota hospital. AIDS Patient Care STDS. 2007;21(5):356-365.

9. NYCDOHMH. HIV/AIDS in Foreign-Born New Yorkers. New York, NY: HIV Epidemiology and Field Services Program New York City Department of Health and Mental Hygiene; 2009.

10. Minnesota Department of Health (MDH). HIV Surveillance Report, 2015. Available from: http://www.health.state.mn.us/divs/idepc/ diseases/hiv/stats/2015/inc2015.pdf. Accessed November 17, 2016.

11. Minnesota Department of Health (MDH). HIV Prevalence and Mortality Report, 2015. Available from: http://www.health.state.mn.us/divs/ idepc/diseases/hiv/stats/2015/pm2015.pdf. Accessed November 17, 2016.

12. Ellis NT. Risks and co-factors among women related to HIV infection and AIDS Treatment. Health Educ. 2000;18(1):7.

13. Meyer JP, Womack JA, Gibson B. Beyond the pap smear: gender-responsive HIV care for women. Yale J Biol Med. 2016;89(2): 193-203.

14. Centers for Disease Control and Prevention [webpage on the Internet]. National Center for HIV/AIDS, Viral Hepatitis, STD, and TB Prevention. 2015 Sexually Transmitted Diseases Surveillance [updated November 23, 2016]. Available from: https://www.cdc.gov/std/stats15/. Accessed March 6, 2017.

15. Minnesota Department of Health. STD Surveillance Report, 2015. Available from: http://www.health.state.mn.us/divs/idepc/dtopics/stds/ stats/2015/stdslides2015.pdf. Accessed March 6, 2017.

16. Foley EE. HIV/AIDS and African immigrant women in Philadelphia: structural and cultural barriers to care. AIDS Care. 2005;17(8): 1030-1043.

17. Tompkins M, Smith L, Jones K, Swindells S. HIV education needs among Sudanese immigrants and refugees in the Midwestern United States. AIDS Behav. 2006;10(3):319-323.

18. De Jesus M. HIV/AIDS and immigrant Cape Verdean women: contextualized perspectives of Cape Verdean community advocates. Am J Community Psychol. 2007;39(1-2):121-131.

19. Othieno J. Understanding how contextual realities affect African born immigrants and refugees living with HIV in accessing care in the Twin Cities. J Health Care Poor Underserved. 2007;18(3):170-188.

20. Mitha K, Yirsalign M, Cherner M, McCutchan A, Langford TD. Risk perception and beliefs regarding HIV infection among Ethiopian immigrants. AIDS Educ Prev. 2009;21(5):484.

21. Blackwood R [webpage on the Internet]. Participatory Needs Assessment. Public Health Textbook. 2009. Available from: http://www. healthknowledge.org.uk/public-health-textbook/research-methods/1chealth-care-evaluation-health-care-assessment/participatory-needsassessment. Accessed November 18, 2016.

22. Mbonu NC, van den Borne B, De Vries NK. Stigma of people with HIV/AIDS in sub-Saharan Africa: a literature review. J Trop Med. 2009;2009:145891.

23. Bond V, Chase E, Aggleton P. Stigma, HIV/AIDS and prevention of mother-to-child transmission in Zambia. Eval Program Plann. 2002; 25(4):347-356.

24. Petros G, Airhihenbuwa CO, Simbayi L, Ramlagan S, Brown B. HIV/ AIDS 'othering' in South Africa: the blame goes on. Cult Health Sex. 2006;8(1):67-77.

25. Simbayi LC, Kalichman S, Strebel A, Cloete A, Henda N, Mqeketo A. Internalized stigma, discrimination and depression among men and women living with HIV/AIDS in Cape Town, South Africa. Social Sci Med. 2007;64(9):1823-1831. 
26. Strebel A, Crawford M, Shefer T, et al. Social constructions of gender roles, gender-based violence and HIV/AIDS in two communities of the Western Cape, South Africa. SAHARA J. 2006;3(3):516-528.

27. Kirtley S, Chien P. Women out loud: how women living with HIV will help the world end AIDS. BJOG. 2013;120(5):652.

28. Visser M. Women, HIV and stigma. Future Virol. 2012;7(6): 529-532.

29. Durevall D, Lindskog A. Intimate partner violence and HIV in ten sub-Saharan African countries: what do the Demographic and Health Surveys tell us? Lancet Glob Health. 2015;3(1):e34-e43.

30. Onsomu EO, Abuya BA, Okech IN, Rosen DL, Duren-Winfield V, Simmons AC. Association between domestic violence and HIV serostatus among married and formerly married women in Kenya. Health Care Women Int. 2015;36(2):205-228.

31. Shi CF, Kouyoumdjian FG, Dushoff J. Intimate partner violence is associated with HIV infection in women in Kenya: a cross-sectional analysis. BMC Public Health. 2013;13(1):1.

32. Shannon K, Leiter K, Phaladze N, et al. Gender inequity norms are associated with increased male-perpetrated rape and sexual risks for HIV infection in Botswana and Swaziland. PLoS One. 2012;7(1):e28739.

33. Jewkes RK, Dunkle K, Nduna M, Shai N. Intimate partner violence, relationship power inequity, and incidence of HIV infection in young women in South Africa: a cohort study. Lancet. 2010;376(9734):41-48.

34. Duffy L. Culture and context of HIV prevention in rural Zimbabwe: the influence of gender inequality. J Transcult Nurs. 2005;16(1):23-31.

35. Buvé A, Bishikwabo-Nsarhaza K, Mutangadura G. The spread and effect of HIV-1 infection in sub-Saharan Africa. Lancet. 2002; 359(9322):2011-2017.

36. UNAIDS. The Gap Report. 2014. Available from: http://www.unaids. org/sites/default/files/media_asset/UNAIDS_Gap_report_en.pdf. Accessed November 18, 2016.
37. Beyrer C, Baral SD, van Griensven F, et al. Global epidemiology of HIV infection in men who have sex with men. Lancet. 2012; 380(9839):367-377.

38. Beyrer C, Sullivan P, Sanchez J, et al. The increase in global HIV epidemics in MSM. AIDS. 2013;27(17):2665-2678.

39. Langen TT. Gender power imbalance on women's capacity to negotiate self-protection against HIV/AIDS in Botswana and South Africa. Afr Health Sci. 2005;5(3):188-197.

40. Padela AI, Gunter K, Killawi A, Heisler M. Religious values and healthcare accommodations: voices from the American Muslim community. J Intern Med. 2012;27(6):708-715.

41. McLean M, Al Yahyaei F, Al Mansoori M, Al Ameri M, Al Ahbabi S, Bernsen R. Muslim women's physician preference: beyond obstetrics and gynecology. Health Care Women Int. 2012;33(9):849-876.

42. Onyemocho A, SonnyJohnbull O, Umar AA, et al. Preference for health provider's gender amongst women attending obstetrics/gynecology clinic, ABUTH, Zaria, Northwestern Nigeria. Am J Public Health Res. 2014;2(1):21-26.

43. Burgoyne AD, Drummond PD. Knowledge of HIV and AIDS in women in sub-Saharan Africa. Afr J Reprod Health. 2008;12(2):14-31.

44. Drummond PD, Mizan A, Brocx K, Wright B. Using peer education to increase sexual health knowledge among West African refugees in Western Australia. Health Care Women Int. 2011;32(3):190-205.

45. Drummond PD, Mizan A, Wright B. HIV/AIDS knowledge and attitudes among West African immigrant women in Western Australia. Sex Health. 2008;5(3):251-259.
International Journal of Women's Health

\section{Publish your work in this journal}

The International Journal of Women's Health is an international, peerreviewed open-access journal publishing original research, reports, editorials, reviews and commentaries on all aspects of women's healthcare including gynecology, obstetrics, and breast cancer. The manuscript management system is completely online and includes

\section{Dovepress}

a very quick and fair peer-review system, which is all easy to use. Visit http://www.dovepress.com/testimonials.php to read real quotes from published authors. 